Development of the Butt Joint for the ITER Central Solenoid

N. N. Martovetsky

August 23, 2006

Applied Superconductivity Conference Seattle, WA, United States August 27, 2006 through September 1, 2006 
This document was prepared as an account of work sponsored by an agency of the United States Government. Neither the United States Government nor the University of California nor any of their employees, makes any warranty, express or implied, or assumes any legal liability or responsibility for the accuracy, completeness, or usefulness of any information, apparatus, product, or process disclosed, or represents that its use would not infringe privately owned rights. Reference herein to any specific commercial product, process, or service by trade name, trademark, manufacturer, or otherwise, does not necessarily constitute or imply its endorsement, recommendation, or favoring by the United States Government or the University of California. The views and opinions of authors expressed herein do not necessarily state or reflect those of the United States Government or the University of California, and shall not be used for advertising or product endorsement purposes. 


\title{
Development of the Butt Joint for the ITER Central Solenoid
}

\author{
Nicolai N. Martovetsky
}

\begin{abstract}
The ITER Central Solenoid (CS) requires compact and reliable joints for its Cable-in-Conduit Conductor (CICC). The baseline design is a diffusion bonded butt joint. In such a joint the mating cables are compacted to a very low void fraction in a copper sleeve and then heat treated. After the heat treatment the ends are cut, polished and aligned against each other and then diffusion bonded under high compression in a vacuum chamber at $750 \mathrm{C}$. The jacket is then welded on the conductor to complete the joint, which remarkably does not require more room than a regular conductor. This joint design is based on a proven concept developed for the ITER CS Model Coil that was successfully tested in the previous $R \& D$ phase.
\end{abstract}

Index Terms - Superconducting cables, power cable connecting, superconducting magnets.

\section{INTRODUCTION}

$\mathrm{T}_{\mathrm{p}}^{\mathrm{H}}$ HE main function of ITER Central Solenoid (CS) is to produce sufficient amount of magnetic flux for plasma initiation and Ohmic heating. The CS has 6 identical modules, each is made out of 7 lengths of Cable in Conduit Conductor (CICC) connected with joints. CICC joints are complex and expensive units. Usually their purpose is to maintain low resistance and provide pressure barrier. The ITER CS requires additionally high strength and low losses. Two types of joint were developed during ITER R\&D on the CS Model Coil. One was a lap joint, developed by the US and by Japanese teams. Another type was a butt joint, developed by only the Japanese team for a layer to layer joint in a "praying hands" configuration, using a hairpin jumper between the layers. Both types of joints demonstrated relatively low DC resistance on the level of 1-3 nOhm [1]. Both types of joint have advantages and disadvantages. The lap joint design is more structurally reliable and offers a better uniformity in current distribution [2]. The butt joint had lower AC losses and was insensitive to orientation of the transverse varying magnetic field [3]. Based on successful CS Model coil experience, ITER selected an in-line butt joint that would occupy about the same space envelop as the conductor. Such a

Manuscript received August 29, 2006. This work was supported by the US Department of Energy under contract to the Lawrence Livermore National Laboratory (contract No. W-7405-Eng-48).

The author is with Lawrence Livermore National Laboratory, Livermore, CA 94550 USA (telephone: (925) 422 4269, e-mail: martovetsky1@llnl.gov) compact joint is very attractive for ITER, since it allows embedding the joint into the winding pack that gives maximum magnetic flux at given peak field in the winding [4].

A similar type of butt joint was successfully developed in early 80 -s by a resistive welding process by Westinghouse [5] and demonstrated consistently low resistance and high strength. However, for ITER conductor this method was tried and rejected due to the inability to produce consistently low resistance joints. The resistive welding at the interface was replaced with the diffusion bonding process [6]. During the CS Model Coil program this method was proven to produce consistently low resistance joints on the ITER type CICC $[1,4]$.

\section{REQUIREMENTS}

Usually joints for CICC magnets are located outside the winding pack in a low field area and are not subject to large magnetic fields and forces. The CS joints are embedded in the winding pack; will see magnetic field up to $2.5 \mathrm{~T}$ and will experience a cyclic load.

The CS joint should meet the following requirements: 1) have acceptably low resistance (less than $5 \mathrm{nOhm}$ ), 2) ensure good distribution of the current between the strands (no premature quenches) 3) be compact, not significantly larger than the CS conductor in cross section and 4) work in cycling conditions of the winding pack up to $0.1 \%$ strain for 60000 cycles. Since the last two requirements are new for a CICC joint, development and thorough qualification is required.

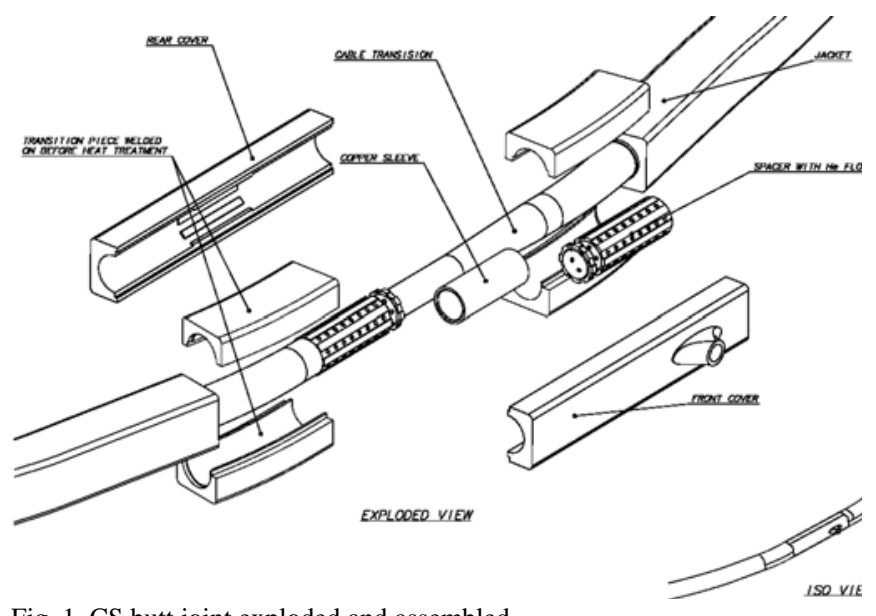

Fig. 1. CS butt joint exploded and assembled.. 


\section{Butt Joint Design}

The joint interface is made between two butts of the mating cables, compacted in copper sleeves. The CS butt joint is shown in Fig.1. In the interface of the joint the strands are highly compacted to a very low void fraction - (5-8\%) to ensure large area of the contact. Studies performed by the Japanese Home Team [3] revealed that the diffusion bond takes place only between copper portions of the cross section in the superconducting strands, sleeve and copper strands. The bronze area does not fuse. Therefore, for the structural integrity of the joint, we need to maintain substantial amount of copper in the butt cross section, including the copper sleeve.

To provide cooling for the cable and the joint interface the conductor has two flow distributors. The first is a conical flow distributor, which is seen in Fig. 2 as a cone with holes, that is inserted into the central spiral. The second is a cylindrical flow distributor, labeled "spacer" in Fig. 1 that provides channels and holes to the outer diameter of the cable.

Fig. 2 shows sequence of the CICC preparation for making a butt joint. First, the jacket is removed to expose the cable. Special tools were developed for this operation during ITER EDA R\&D. At the second step, the cable is dismantled, the central spiral is removed and replaced with the conical flow distributor. Third, a transition piece is welded to the jacket and the cable is inserted into the steel spacer. Then, the copper sleeve is installed and the cable is compacted in the sleeve. Forth, the strand ends are sealed to prevent tin leaking during

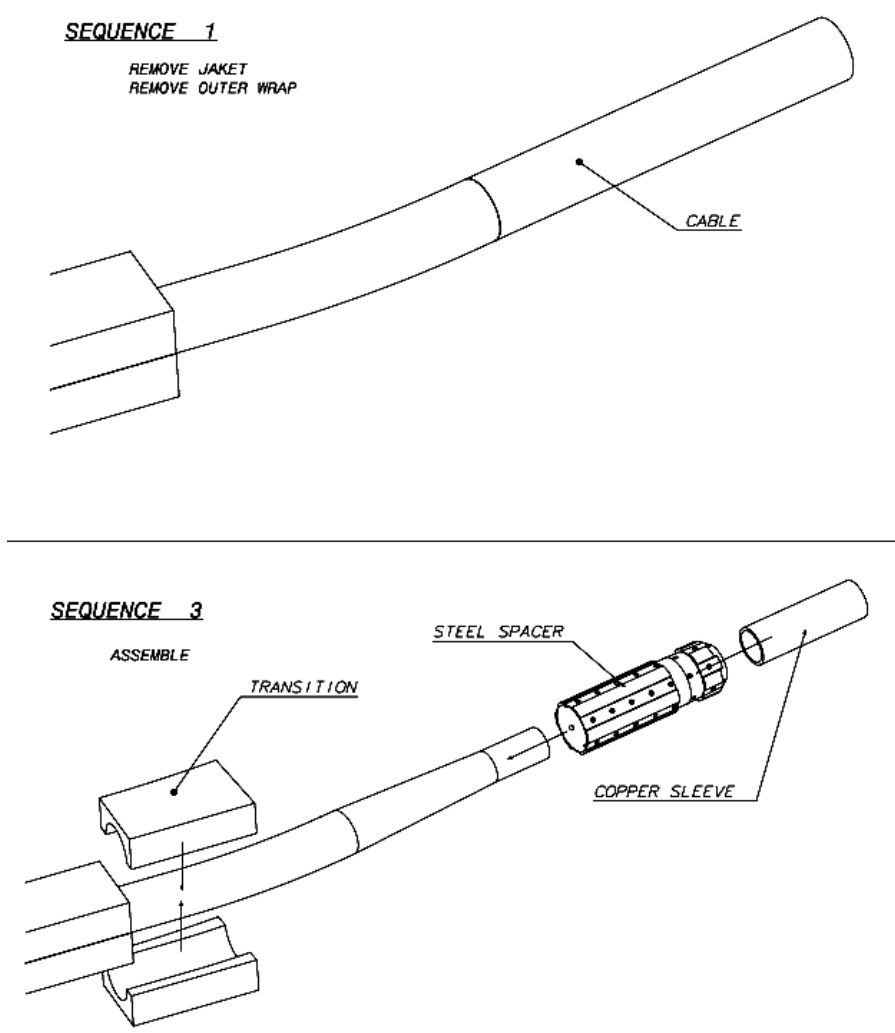

Fig. 2. Butt joint assembly procedure and parts the heat treatment and then a temporary sheath is welded onto the transition piece to protect the cable during heat treatments of the conductor. These most critical preparations are shown in Fig. 2. After heat treatment, the protective sheath is removed, the cable in the copper sleeve is carefully cut, polished and aligned. At this step we will install a butt joint tool and make the joint. After the joint is made, the butt joint tool is dismantled and the conduit parts (see Fig. 1) are fit and welded around the cable and the butt joint restoring conductor strength and pressure boundary.

We are unable to easily check joint resistance without great expenses. Due to criticality of the joint for the CS performance, making the butt joint will require intensive qualification and adequate QA/QC provisions for fabrication.

Qualification of the butt joint includes demonstration of the joint performance under the tensile cyclic load. The butt joint operating conditions were analyzed and that determined the requirements for the joint qualification.

\section{Structural Analysis of the Butt Joint}

The CS winding pack outer diameter will experience tensile strain up to $0.1 \%$. Since butt joints are embedded in the winding pack, the jacket surrounding the joint will experience this strain. Structural analysis of the butt joints local model [7] showed that there is a significant stress concentration factor in the jacket at the area near the outlet penetration of the jacket up to $700 \mathrm{MPa}$. However, despite large stresses the JK2LB steel developed for the CS CICC jacket should be able to withstand this fatigue load with a comfortable safety margin.

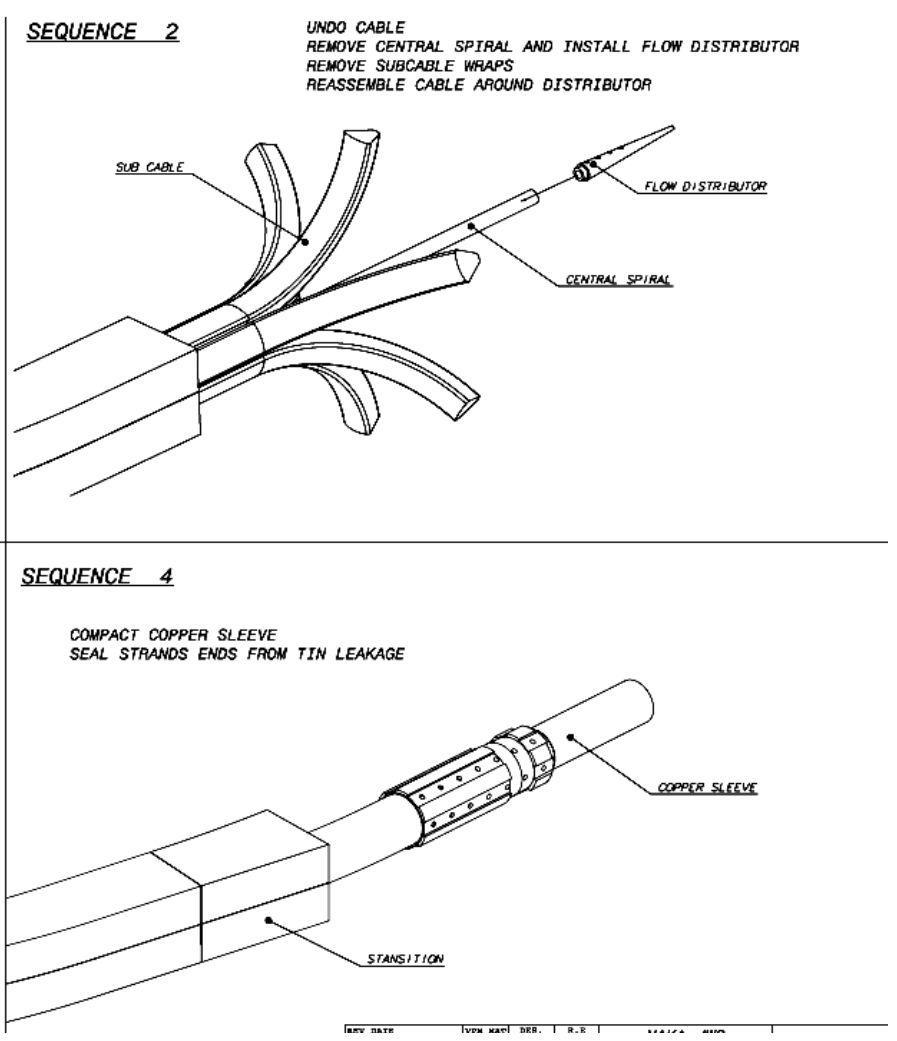




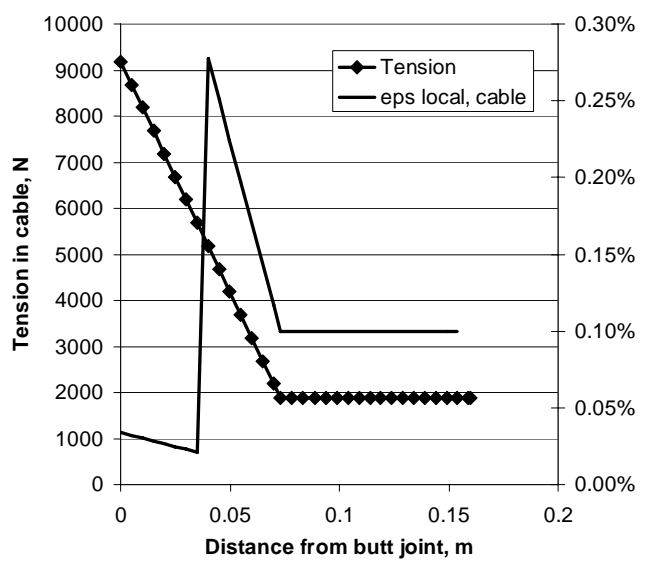

Fig. 4. Tension and strain in the joint and adjacent cable at friction coefficient $\mathrm{f}=1$.

stiff compacted portion of the cable in the copper sleeve and the jacket wall by Teflon coating of the flow distributor and

Fig. 3. Forces on the butt joint and the CS cable.

Another local analysis [8] showed that welding steel profiles to build a jacket around the butt joint represents a significant challenge. The stress concentration factor could be as high as 4.6, leading to a Tresca stress up to $920 \mathrm{MPa}$ in the jacket welds, which is too high for the required service life. Some optimization of the conduit weld design is required to reduce the stress concentration; then the conduit welds will be qualified and the QA provisions established.

The stresses in the butt joint were also analyzed using several models. Study [7] performed with ANSYS predicted that the strain of the butt joint interface will be stretched by only slightly less than the jacket - to $0.1 \%$, and the butt joint interface will see $22 \mathrm{kN}$ tensile load. At ultimate strength of the butt joint of $40-50 \mathrm{kN}$ [3] there is a serious concern regarding mechanical and electrical integrity of the joint under such high cyclic load.

An assessment [8] suggested that the forces could be a little lower, at $17-18 \mathrm{kN}$.

Another analytical study of the butt joint stresses [9] considered in more details the interaction between the cable and the jacket during electromagnetic loading of the CS.

Fig. 3 shows forces acting on the cable and the butt joint. The friction force $\mathrm{F}$ acts on the cable and pulls it with a tensile force $T(x)$. At the interface the force $Q$ is the tensile force in question. L1 is the length of the stiff cable compressed in the copper sleeve, and $L^{*}$ is the length where jacket is slipping relative to the cable and joint.

Due to low stiffness of the cable the strain at the butt joint interface will be significantly lower and there will be a slippage between the compacted sleeve and the jacket. This will occur because the length of the sleeve is not sufficient to accumulate enough pulling force from the jacket to the compacted cable. Fig. 4 shows distribution of the strain and tensile force in the cable. The soft cable stretches more than a rigid cable in the sleeve and thus reduces separating force in the joint.

Even at a very conservative coefficient of friction of 1 , the tension on the butt joint interface is only fraction of the butt joint anticipated strength.

If we can maintain a low coefficient of friction between the the jacket, tension in the butt joint could be reduced significantly.

One should keep in mind that the reliability of the assumed properties of the parts of the joint and the cable are not verified by testing. Meanwhile results of the analysis are heavily dependent on the assumed properties. Therefore one of the tasks in the butt joint testing is to verify mechanical properties of the joint parts and distribution of strain.

\section{QUALIFICATION OF THE BUTT JOINT}

The procedures for qualifying the butt joint is summarized here. A minimum of five full-scale heat treated CS CICC samples, approximately $1 \mathrm{~m}$ each with the butt joint will be fabricated in accordance with the developed specification.

After the joint is made, a visual inspection of the joint deformation, defects and imperfections will be carried out.

Two samples will be used for metallographic studies. For that the piece of the compacted cable including the interface is cut out, de-sectioned in two planes parallel to the conductor axis and then polished. Observation with a magnifying glass $\mathrm{x} 10$ and in good light conditions shall demonstrate that every strand is robustly diffusion bonded and that the strands are not deformed during this procedure, (no mushrooming).

After that, three samples will be prepared for fatigue test and ultimate test in the tensile machine without the conduits at $\mathrm{LN}_{2}$ temperature.

The fatigue tests with the constant strain of $0.1 \%$ will demonstrate that the joint can withstand 60,000 cycles with sufficient margin.

After the fatigue tests the ultimate tensile strength of the joint will be performed. The acceptance criterion for the butt joint rupture force is greater than $40 \mathrm{kN}$ without jacket support.

After qualification of the mechanical properties of the joint we will qualify the butt joint electrical performance and sensitivity to the cyclic loading.

We will make full scale samples and test them in the Pulsed Test Facility at MIT PSFC [10] for electrical resistance. Then the samples will be subjected to cycling up to $0.1 \%$ strain and after the cycling we will retest them at the PTF. Unfortunately, it is prohibitively expensive to combine the 


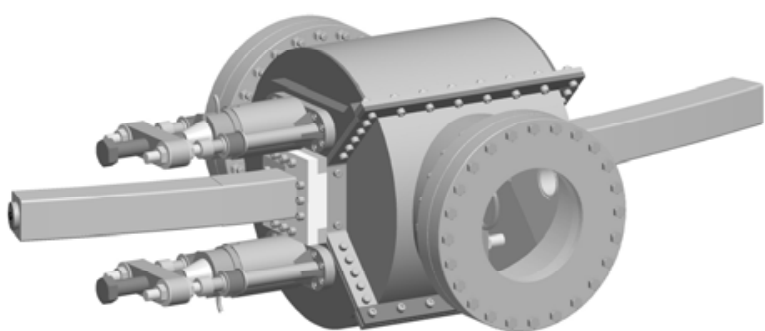

Fig. 5. Butt joint tool mounted around joint. On the left flange a loading mechanism with pulling rods is shown.

cyclic testing in LHe with current. The mechanical testing will have to be done in a separate facility at $77 \mathrm{~K}$.

\section{BUTT JOINT FABRICATION}

The butt joint fabrication procedure of bonding was developed during ITER EDA [3]. The CS butt joint will use these parameters as a starting point and will verify its applicability to the CS conductor. The butt joint is formed under pressure of $30 \mathrm{MPa}$ at $750 \mathrm{C}$ in for 70 minutes in a vacuum better than $0.5 \mathrm{~Pa}$.

The apparatus for making a butt joint is shown in Fig. 5 . The tool must be split to be mounted over the conductors, and this makes it significantly more difficult than the tool used for the CS Model Coil butt joints [3]. Another problem is that the straight length of the conductor in the joint area is only 320 $\mathrm{mm}$ so the vacuum seal between the vacuum vessel and the conductor will have to be made only 140-150 mm away from the interface that is heated to $750 \mathrm{C}$. Heat transfer by a massive cable with high content of copper over a short distance represents a substantial technical challenge for the

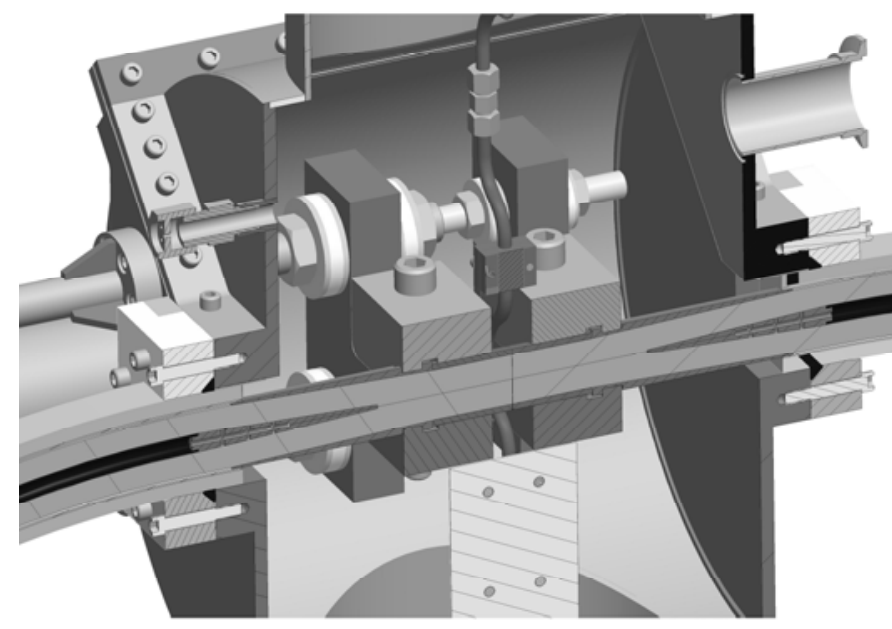

Fig. 6. Cross section of the butt joint in the butt joint tool. Induction heater coil embraces the joint interface and generates heat at the interface. The conductor is sealed with the O-ring.

seal. Thermal analysis showed that if the conductor jacket is water cooled immediately near the seal, the commercial elastomers should be able to withstand high temperatures and maintain the vacuum.

The cross section of the butt joint tool is given in Fig. 6. It shows the clamps holding the joining parts of the conductors and an induction heater coil generating heat at the butt joint interface.

The compression of the joining parts is produced by the screws outside the vessel as shown in Fig. 5 on the left side. When the screws are tightened, they push on the stack of the spring washers and pull the rods going into the chamber. The rods pull the clamps, which compress the joining butts up to $30 \mathrm{MPa}$ pressure at the joint interface.

\section{CONCLUSION}

The CS butt joint is one of the high risk critical elements of the CS. Although many feasibility issues were addressed in the previous ITER R\&D, some requirements make this joint a unique object, which requires qualification, development of special tools and QA provisions, including full scale conductor testing in a specialized facility.

The qualification of the butt joint is planned to be completed in 2007-2008.

\section{ACKNOWLEDGMENT}

The author is grateful to Y. Takahashi, M. Sugimoto, P. Titus, W. Meier and J. Bowers for useful discussions and suggestions.

\section{REFERENCES}

[1] N. Martovetsky, P. Michael, J. Minervini, A. Radovinsky et al, "Test of the ITER Central Solenoid Model Coil and CS Insert”, IEEE Trans. Appl. Supercond. vol.12, no. 1, p. 600-605, March 2002.

[2] N. Martovetsky, J. Jayakumar, R. Manahan, P. Michael et al, "Development and Test of the ITER Conductor Joints for the central solenoid” Fusion Technology, 1998; vol 34; no 3, p. 808-814

[3] Y. Takahashi, Y. Nunoya, G. Nishijima et al, "Development of 46-kA Nb3Sn Conductor Joint for ITER Model Coils", IEEE Trans. Appl. Superconductivity, vol. 10, No 1, pp.580-583, March 2000.

[4] Y. Takahashi, K. Yoshida, N. Mitchell, D. Bessette, Y. Nunoya, K. Matsui, N. Koizumi, T. Isono, K. Okuno, "Performance of Joints in the CS Model Coil and Application to the Full Size ITER Coils” IEEE Trans. Appl. Supercond. vol.14, no. 2, p. 1410-1413, March 2000.

[5] A.J. Jarbak, T.D. Hordubay, R.D. Fetzko and J.B. Tobias, "In the Westinghouse LCP coil", in Proc. $9^{\text {th }}$ Symposium on Eng. Problems of Fus. Research, vol. II, p. 778, Chicago, 1981.

[6] Y. Takahashi, private communication.

[7] M. Sugimoto, "Final report of Structural Assessment on the Helium Inlet and Joint in the CS", ITER Task Agreement Report by JAERI, Task ITA-11-38, December 16, 2005, unpublished.

[8] P. Titus, "Jacket Butt Weld Design/Stress" Memo, ITER/US/MIT/PTitus/06-13-2006-1, unpublished

[9] N. Martovetsky, "Forces on the butt joint interface", LLNL memorandum, December 15, 2005.

[10] B. Smith, J. R. Hale, A. Zhukovsky et al, "PTF, a new facility for pulse field testing of large scale superconducting cables and joints", IEEE IEEE Trans. Appl. Superconductivity, vol. 7, No 2, pp.1049-1052, June 1997. 